\title{
PENGEMBANGAN ALTERNATIF DESAIN PERBAIKAN ALAT POTONG KERIPIK PISANG (STUDI KASUS DI HOME INDUSTRI PEMBUATAN KERIPIK PISANG DESA BANGSRI, KECAMATAN KERTOSONO, KABUPATEN NGANJUK)
}

\author{
Andriawan Haryo Nugroho, Dedy Kunhadi \\ Jurusan Teknik Indsutri \\ Universitas WR. Supratman Surabaya \\ Email : nur.rafiansyah02@gmail.com
}

ABSTRAK

\begin{abstract}
A lat potong bahan baku keripik pisang modifikasi yang merupakan hasil kreasi dari kondisi alat potong yang digunakan saat ini masih sederhana, kurang efisien dan kurang efektif. Alat yang berfungsi sebagai pemotong adalah berupa alat potong yang biasa digunakan untuk mengolah bahan - bahan yang akan dimasak menjadi sayur.

Metode rekayasa nilai digunakan sebagai metode untuk memilih satu alternatif modifikasi pada alat potong modifikasi dan menganalisanya melalui tahapan lima rencana kerja. Pada tahap analisa dipilih 3 alternatif modifikasi dari perbaikan mesin ditambah 1 desain awal, dimana desain awal digunakan sebagai patokan dalam penilaian performansi. Hasil penentuan nilai pada tahap pengembangan diperoleh bahwa alternatif modifikasi ke 1 mempunyai nilai 0.79 dengan performansi 172.072 dengan memberikan keuntungan yaitu : proses pemotongan lebih cepat, perawatan mudah, hasil potongan relatif bersih dan rapi, langkah potong lancar dan ringan, keselamatan operator lebih baik
\end{abstract}

Kata Kunci : alat potong modifikasi, alternatif modifikasi, rekayasa nilai

\section{PENDAHULUAN}

Krisis ekonomi yang berkepanjangan yang melanda beberapa negara di kawasan Asia Tenggara menjadikan adanya hambatan-hambatan secara simultan terhadap pelaksanaan pembangunan. Hal ini sangat terasa sekali di negara Indonesia sebagai salah satu negara berkembang dimana segala sektor pembangunan mengalami kemacetan. Dengan demikian secara tidak langsung proyekproyek vital baik milik pemerintah maupun swasta menjadi lambat bahkan macet. Hal tersebut akan menjadi parah manakala melambungnya harga barang / material maupun semakin tingginya nilai tukar rupiah terhadap mata uang asing, khususnya dollar AS.

Menghadapi situasi perekonomian yang tidak menentu seperti ini, bentuk usaha yang merasa sangat terpukul dengan hal ini adalah usaha dalam skala kecil dan menengah yang sering disebut dengan usaha home industri yang memiliki modal usaha yang terbatas.

Kelancaran proses produksi banyak dipengaruhi dari kondisi fasilitas produksi yang dimiliki. Dalam studi kasus yang dilakukan pada usaha home industri pembuatan keripik pisang di desa Bangsri,
Kecamatan Kertosono, Kabupaten Nganjuk, maka perlu memperhatikan fasilitas produksi yang digunakan pada home industri tersebut khususnya alat potong masih sangat sederhana yakni hanya menggunakan alat potong sederhana yang biasa dijual di pasaran yang biasa digunakan untuk memotong bawang merah / bawang putih, pepaya dan bahan - bahan lain yang umum dimanfaatkan untuk keperluan memasak sayur sehari - hari. Dengan kondisi alat potong yang digunakan tersebut menyebabkan kurangnya kuantitas hasil potong setiap harinya. dan waktu yang diperlukan relatif lama

Selain itu untuk mereduksi biaya produksi, maka bentuk irisan dari pisang yang selama ini berbentuk memanjang akan dirubah menjadi bulat. Perubahan bentuk irisan ini diharapkan dapat membantu mengurangi biaya produksi dalam beberapa hal, antara lain : penggunaan plastik pembungkus yang dimensinya dapat diperkecil dengan bobot isi keripik yang sama, penghematan bahan bakar dalam proses penggorengan yang mana proses penggorengan akan lebih cepat karena dimensi potongan pisang yang lebih kecil sehingga dalam sekali proses goreng dapat menampung jumlah pisang yang jumlahnya lebih banyak, yang 
akhirnya diharapkan dapat mempersingkat waktu proses produksi secara keseluruhan.

Berdasarkan permasalahan tersebut diatas, maka perlu untuk mengusulkan perbaikan atau pengembangan peralatan kerja di bagian pemotongan yang merupakan bagian vital dalam usaha ini. Alternatif yang dikembangkan pada fasilitas alat potong di tekankan pada cara pengoperasiannya. Dimana aktivitas modifikasi alat potong pada dasarnya merupakan sebuah pengkreasian yang akhirnya kesemuanya ini akan menjadi kurang berarti bilamana tidak memperhatikan keluaran hasil dari produk yang dibuat dan hanya akan menjadikan biaya manufaktur pada proses bersangkutan menjadi lebih mahal.

\section{METODOLOGI}

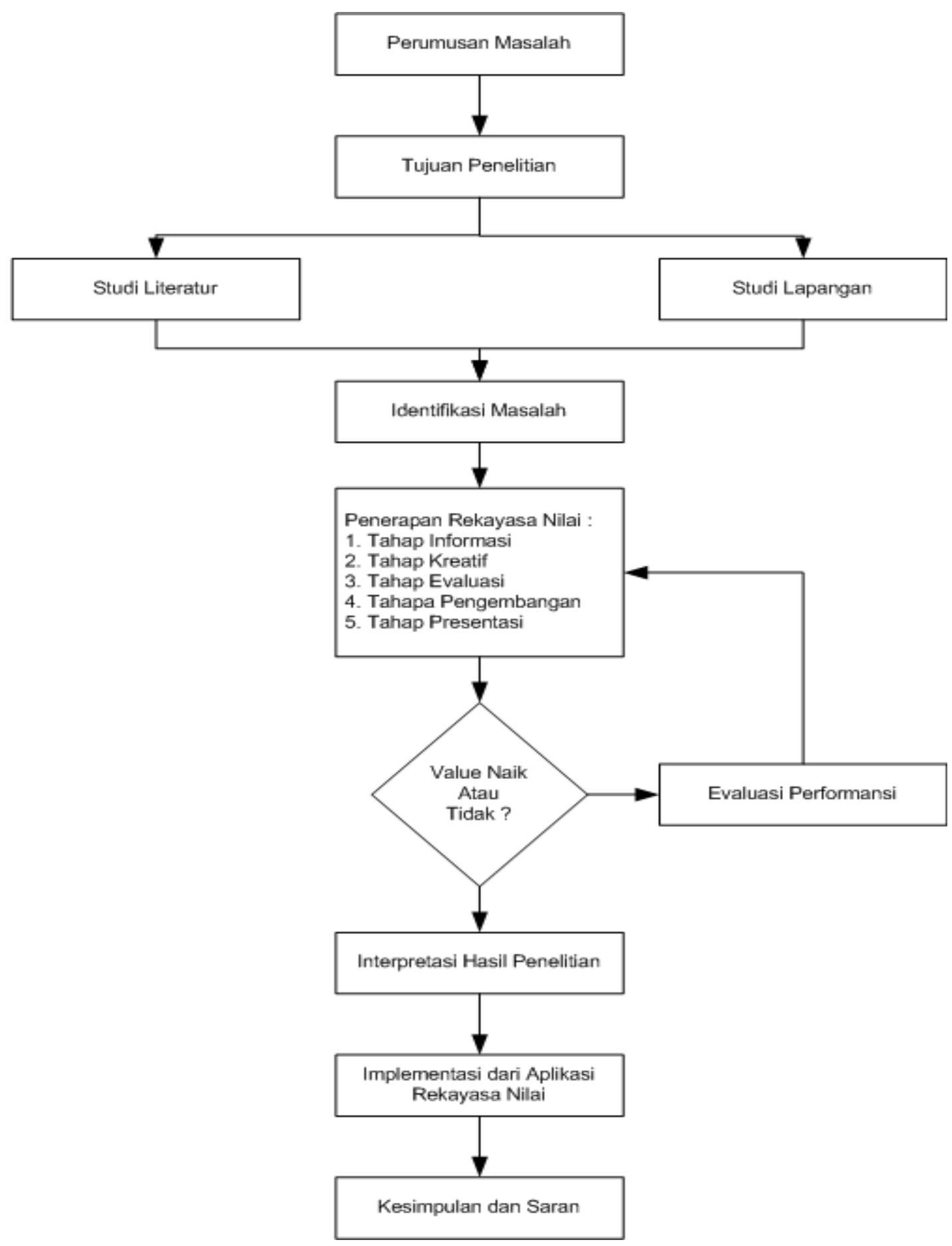




\section{HASIL DAN PEMBAHASAN}

\section{Tahap Informasi}

Komponen gerakan pokok untuk menunjang terjadinya proses pemotongan bahan baku keripik pisang pada alat potong modifikasi dari aktivitas proses pemotongan bahan baku keripik pisang, dapat dijelaskan yaitu antara lain :

1. Merubah cara pengoperasian dengan menggunakan rotor putar yang digerakkan manual dengan tangan, rotor ini dihubungkan dengan besi bulat pejal yang berfungsi menghubungkan rotor penggerak dengan pengumpan bahan baku keripik pisang, meneruskan energi dan merubah gerak putar rotor menjadi gerak maju mundur pada pengumpan bahan baku keripik pisang. Prinsip kerjanya seperti poros engkol pada mesin motor yang dapat meneruskan dan merubah gerak naik turun piston menjadi gerak putar. Pemilihan cara pengoperasian masih menggunakan cara manual bertujuan untuk meminimalkan biaya yang dikeluarkan.

2. Menempatkan alat pengumpan bahan sehingga operator tidak perlu memegang dan mengumpankan bahan pada pisau. Alat pengumpan terbuat dari pipa besi yang memiliki diameter dalam $39 \mathrm{~mm}$, berjumlah dua buah dan keduanya direkatkan langsung menggunakan las listrik. Penempatan alat pengumpan ini bertujuan untuk mempercepat proses pemotongan karena proses pemotongan dapat berlangsung secara kontinu.

3. Posisi pisau potong berada dibawah pipa pengumpan. Pisau diletakkan pada media dudukan pisau yang terbuat dari kayu. Media ini terdiri dari dua bagian, yang pertama sebagai dudukan pisau dan yang kedua berfungsi sebagai pengatur ketebalan potongan bahan. Prinsip kerja alat potong ini sama dengan alat serut kayu.

4. Ujung dudukan pisau dibuat miring $45^{\circ}$, hal ini juga diterapkan pada pengatur ketebalan potongan. Ujung yang miring ini berfungsi sebagai sudut buang dari pisau potong.

5. Bahan baku yang terpotong ditampung dalam wadah yang diletakkan dibawah alat potong. Wadah ini tidak termasuk dalam fasilitas alat potong.

Pada dasarnya alat potong yang telah ada yang dipakai untuk proses pemotongan bahan baku keripik pisang kurang efektif dan efisien. Masalah terutama dikarenakan oleh penggunaan alat potong yang mana pengoperasiannya dipegang langsung dengan satu tangan dan tangan yang satu bertugas untuk mengumpankan bahan baku pada pisau potong, hal ini kurang efektif dan efisien karena selain membutuhkan waktu yang relatif lama selain itu tangan operator akan mudah lelah karena harus memberikan gaya tekan yang kontinu pada bahan baku dan harus menahan alat potong agar tetap kokoh.

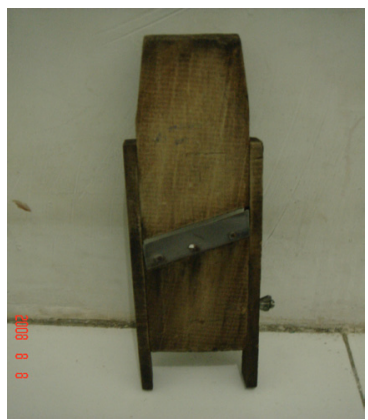

Gambar 1. Alat Potong
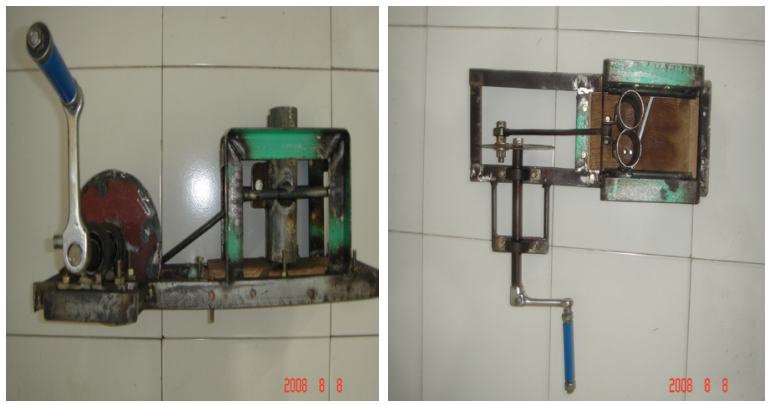

Gambar 2. Alat Potong Modifikasi Sederhana

Dalam mengantisipasi kelemahan pada alat potong yang sudah ada maka dibuat alat potong bahan baku keripik pisang modifikasi. Tetapi alat potong bahan baku keripik pisang modifikasi masih terus harus dikembangkan terutama pada mekanisme kerja alat agar dapat meningkatkan performansi dari alat potong modifikasi tersebut.

Fungsi yang mendukung dari alat potong bahan baku keripik pisang modifikasi dijelaskan dalam 2 kata kunci yang terdiri dari satu kata kerja dan satu kata benda seperti yang dijabarkan pada tabel 1. berikut ini. 
Tabel 1 Fungsi Alat Potong Modifikasi

\begin{tabular}{|r|c|l|c|}
\hline \multirow{2}{*}{ Komponen } & \multicolumn{2}{|c|}{ Fungsi } & \multirow{2}{*}{ Jenis } \\
\cline { 2 - 3 } & Kata Kerja & \multicolumn{1}{|c|}{ Kata Benda } & \\
\hline \multirow{2}{*}{$\begin{array}{c}\text { Alat Potong } \\
\text { Modifikasi }\end{array}$} & Memberikan & $\begin{array}{l}\text { Kemudahan, } \\
\text { Kehandalan dan } \\
\text { Kenyamanan }\end{array}$ & $\mathrm{P}$ \\
\cline { 2 - 3 } & Memberi & Kualitas dan Kuantitas & $\mathrm{S}$ \\
\hline
\end{tabular}

Diagram FAST dapat dilihat pada gambar 3 , yang menggambarkan tujuan yang akan diselesaikan pada permasalahan penelitian ini, dengan pengembangan alternatif desain perbaikan alat potong, sehingga diharapkan dapat meningkatkan performansi alat potong bahan baku keripik pisang modifikasi.

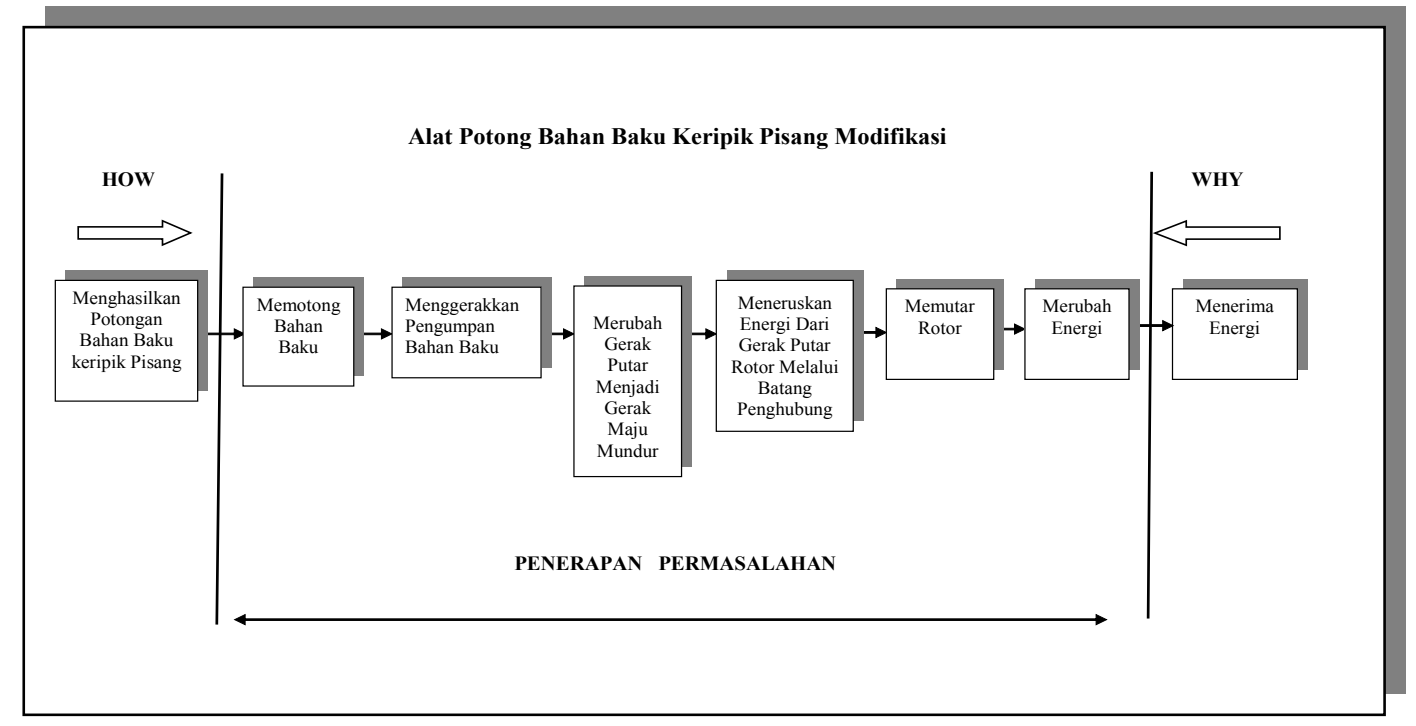

Gambar 3. Diagram FAST Alat Potong Bahan Baku Keripik Pisang Modifikasi

\section{Tahap Kreatif}

Setelah dilakukan pengamatan pendahuluan terhadap bagian elemen-elemen alat potong dari gerakan pokok aktivitas proses pemotongan bahan baku keripik pisang, maka diperoleh dasar pemilihan alternatif awal yang digunakan sebagai obyek pembangunan ide dari alternatif yaitu :

1. Kemampuan alat potong bahan baku keripik pisang modifikasi dalam aktivitas proses pemotongan adonan bahan baku keripik pisang.

2. Transmisi putar pada alat potong adonan kerupuk modifikasi menggunakan rotor yang digerakkan secara manual dengan tangan . hal ini bertujuan untuk meminimalkan biaya perbaikan mengingat modal yang dimiliki oleh home industri ini masih sangat terbatas.

3. Pembuatan pengumpan bahan yang bertujuan agar operator tidak perlu memegang langsung bahan baku untuk diumpankan.

Berdasarkan dari enam gerakan dasar pemilihan alternatif awal dari elemen alat potong adonan kerupuk, maka dapat dikembangkan alternatif desain perbaikan alat potong adonan kerupuk modifikasi, yaitu antara lain : 
Tabel 2 Alternatif Modifikasi

\begin{tabular}{|c|l|}
\hline \multirow{3}{*}{ Modifikasi I } & $\begin{array}{l}\text { Merubah cara pengoperasian dengan menggunakan rotor } \\
\text { manual yang dihubungkan dengan pengumpan bahan. } \\
\text { Pisau potong terbuat dari pisau dapur yang sudah ditempa } \\
\text { permukaannya dan posisi pisau diletakkan diatas permukaan } \\
\text { dudukan pisau dan diikat menggunakan baut persing. }\end{array}$ \\
\hline Modifikasi II & $\begin{array}{l}\text { Merubah cara pengoperasian dengan menggunakan rotor } \\
\text { manual yang dihubungkan dengan pengumpan bahan. Pisau } \\
\text { potong terbuat dari cutter refill yang dijepit dengan plat dengan } \\
\text { tebal 1.8 mm dan posisi pisau diletakkan diatas permukaan } \\
\text { dudukan pisau dan diikat menggunakan baut persing. }\end{array}$ \\
\hline Modifikasi III & $\begin{array}{l}\text { Merubah cara pengoperasian dengan menggunakan rotor } \\
\text { manual yang dihubungkan dengan pengumpan bahan. Pisau } \\
\text { potong terbuat dari cutter refill yang dijepit dengan plat dengan } \\
\text { tebal 1.8 mm dan posisi pisau diletakkan dibawah dudukan } \\
\text { pisau yang permukaannya miring dan diikat menggunakan } \\
\text { baut persing. }\end{array}$ \\
\hline
\end{tabular}

Alternatif modifikasi ini selanjutnya digunakan untuk mempertimbangkan alat potong bahan baku keripik pisang dalam pemilihan mođifikasi pengembangan alternatif desain perbaikan alat potong dari aktivitas proses pemotongan bahan baku keripik pisang.

\section{Tahap Evaluasi}

Tahapan analisa atau tahap evaluasi ini dilakukan dengan beberapa mekanisme analisa antara lain : (1) analisa keuntungan dan kerugian pada alternatif modifikasi yang dibangun,

(2) perhitungan

Tabel 3

Keuntungan dan kerugian Alternatif Modifikasi I

\begin{tabular}{|c|c|}
\hline Keuntungan & Kerugian \\
\hline $\begin{array}{l}\text { - } \\
\text { Proses pemotongan } \\
\text { lebih cepat } \\
\text { - } \text { Perawatan mudah } \\
\text { - Hasil potongan relatif } \\
\text { bersih dan rapi } \\
\text { - } \text { Langkah potong } \\
\text { lancar dan ringan } \\
\text { - Keselamatan operator } \\
\text { lebih baik }\end{array}$ & $\begin{array}{l}\text { Pisau potong harus } \\
\text { lebih sering } \\
\text { dipantau karena } \\
\text { bahan dasar } \\
\text { pisau terbuat dari } \\
\text { baja tempa yang } \\
\text { permukaannya tidak } \\
\text { dilapisi anti karat }\end{array}$ \\
\hline
\end{tabular}
penilaian kriteria yang dibangun dengan matrik kelayakan, (3) analisa pembobotan pada kriteria dan (4) perhitungan performansi dengan matrik evaluasi terhadap alternatif yang terpilih.

\subsection{Analisa Keuntungan dan Kerugian}

Analisa keuntungan dan kerugian untuk tiaptiap alternatif modifikasi yang dilakukan pada alternatif pengembangan desain perbaikan fasilitas dijelaskan pada analisa berikut ini, antara lain :

Tabel 4

Keuntungan dan kerugian Alternatif Modifikasi II

\begin{tabular}{|c|c|}
\hline Keuntungan & Kerugian \\
\hline $\begin{array}{ll}\text { - } & \text { Proses pemotongan } \\
\text { lebih cepat } \\
\text { - } & \text { Perawatan mudah } \\
\text { - } & \text { Keselamatan } \\
& \text { operator lebih baik }\end{array}$ & $\begin{array}{l}\text { Langkah potong } \\
\text { agak tersendat } \\
\text { karena terhalang } \\
\text { plat penjepit pisau } \\
\text { Hasil potongan } \\
\text { kurang rapi karena } \\
\text { permukaan antara } \\
\text { pisau potong } \\
\text { dengan plat penjepit } \\
\text { tidak rata. } \\
\text { Hasil potongan } \\
\text { kurang rapi }\end{array}$ \\
\hline
\end{tabular}


Tabel 5

Keuntungan dan kerugian Alternatif Modifikasi III

\begin{tabular}{|l|ll|}
\hline \multicolumn{1}{|c|}{ Keuntungan } & & \multicolumn{1}{c|}{ Kerugian } \\
\hline$\bullet$ & Proses & Perawatan agak \\
pemotongan & & sulit \\
lebih cepat & $\bullet$ & Langkah potong \\
Keselamatan & & agak kasar karena \\
operator lebih & & pisau menggaruk \\
baik & & bahan baku \\
& $\bullet \begin{array}{l}\text { Hasil potongan } \\
\text { kurang rapi }\end{array}$ \\
& & \\
\hline
\end{tabular}

Selanjutnya dalam penilaian penentuan prioritas kriteria dilakukan melalui penyebaran lembar kuesioner yang berisi pertanyaan mengenai urutan tingkat prioritas kriteria. Pengisian kuesioner dalam penilaian terhadap penentuan tingkat kepentingan, skala nilai yang diberikan terhadap kriteria prioritas sesuai dengan tingkat kepentingannya, maka skala yang digunakan yaitu 1 sampai dengan 10 yaitu sebagai berikut :

$\begin{array}{lll}1 & \vdots & \text { Tidak Penting } \\ 2 & \vdots & \text { Sama Sekali Tidak Penting } \\ 3 & \vdots & \text { Kukun Tidak Penting } \\ 4 & \vdots & \text { Sedikit Penting } \\ 5 & \vdots & \text { Cukup Penting } \\ 6 & \vdots & \text { Penting } \\ 7 & \vdots & \text { Santing Sekali } \\ 8 & \vdots & \text { Sangat Penting } \\ 9 & \vdots & \text { Sangat Penting Sekali }\end{array}$

Tabel 6

Hasil Akhir Penilaian Matrik Evaluasi

\begin{tabular}{|c|c|c|c|c|c|c|}
\hline \multirow[b]{2}{*}{ 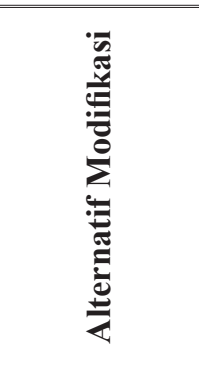 } & \multicolumn{4}{|c|}{ KRITERIA } & \multirow[b]{2}{*}{ 号 } & \multirow[b]{2}{*}{ 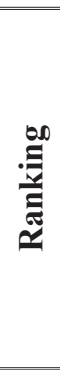 } \\
\hline & 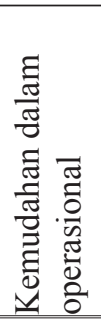 & 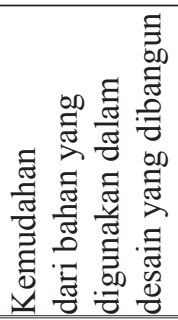 & 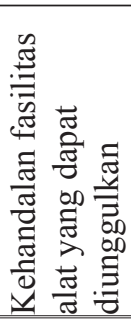 & 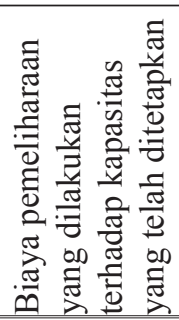 & & \\
\hline Desain awal & 22 & 35 & 25 & 40 & 122 & 4 \\
\hline 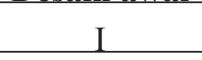 & 50 & 35 & 45 & 39 & 169 & 1 \\
\hline$\amalg$ & 40 & 34 & 34 & 39 & 147 & 3 \\
\hline$\amalg$ & 37 & 36 & 37 & 40 & 150 & 2 \\
\hline
\end{tabular}

Berdasarkan tabel diatas, maka modifikasi I dapat dipertimbangkan untuk ditindak lanjuti sebagai alternatif yang terpilih dalam pengembangan alternatif desain perbaikan alat potong.

\subsection{Analisa Pembobotan Kriteria}

Perhitungan pada pembobotan kriteria diperlukan sebelum menghitung performansi untuk

\subsection{Perhitungan Penilaian Kriteria Dengan Matrik Kelayakan}

Tujuan dilakukan perhitungan dengan menggunakan matrik kelayakan adalah menyeleksi alternatif modifikasi yang diambil agar lebih memenuhi tujuan yang diinginkan. Nilai yang diberikan untuk tiap-tiap kriteria dengan skala nilai yaitu antara skala 0 hingga 10 , dalam pengambilan data yang bersifat kualitatif tidak terlepas dari permasalahan faktor subyektifitas maka untuk mengeleminir faktor subyektifitas dalam melakukan penilaian dilakukan oleh lebih dari 1 orang yang memahami benar dalam proses pemotongan bahan baku keripik pisang.

Dalam penelitian ini penilaian dilakukan terhadap 10 responden yang terdiri 4 responden berasal dari individu yang berpengalaman dalam perancangan dan pembuatan alat tepat guna perbengkelan milik bapak Tarmudjianto di desa Kalianyar Kecamatan Kertosono Kabupaten Nganjuk

Hasil akhir penilaian terhadap kriteria yang diberikan pada ke 4 alternatif dan ditambah 1 alternatif desain awal dapat dijelaskan pada tabel 6 dibawah ini. tiap-tiap kriteria dengan menggunakan metode perbandingan berpasangan berdasarkan pada analytic hierarchy process (AHP) dari tingkat kepentingan. Matrik berpasangan dilakukan untuk menormalisasi pembobotan dengan jalan membagi setiap entri dengan jumlah kolom yang bersangkutan dan akhirnya diperoleh bobot tiap kriteria (eugen vektor), selanjutnya menentukan 
seberapa baik nilai konsistensi dari data yang ada.

Uji konsistensi dilakukan untuk mengetahui sejauhmana nilai bobot yang diperoleh pada banding berpasangan di atas memberikan informasi secara konsisten dari data yang diambil pada kuesioner. Uji konsistensi untuk tiap-tiap nilai bobot dapat dijelaskan pada tabel 7 dibawah ini:

Tabel 7

Matrik Banding Berpasangan Dengan Bobot Kriteria

\begin{tabular}{|c|c|c|c|c|c|c|}
\hline \multirow[t]{2}{*}{ No. } & KRITERIA & 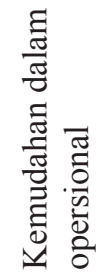 & 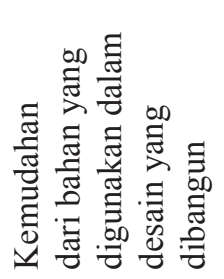 & 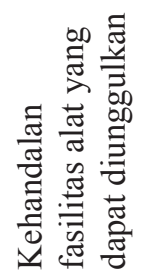 & 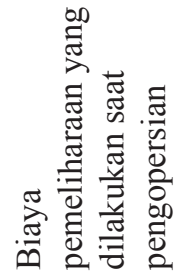 & \multirow[t]{2}{*}{ Jumlah } \\
\hline & & 0.488 & 0.233 & 0.175 & 0.104 & \\
\hline 1 & $\begin{array}{l}\text { Kemudahan dalam } \\
\text { opersional }\end{array}$ & 0.488 & 0.932 & 0.525 & 0.312 & 2,257 \\
\hline 2 & $\begin{array}{l}\text { Kemudahan } \\
\text { dari bahan yang } \\
\text { digunakan dalam } \\
\text { desain yang } \\
\text { dibangun }\end{array}$ & 0.122 & 0.233 & 0.525 & 0.208 & 1,088 \\
\hline 3 & $\begin{array}{l}\text { Kehandalan fasilitas } \\
\text { alat yang dapat } \\
\text { diunggulkan }\end{array}$ & 0.163 & 0.078 & 0.175 & 0.312 & 0.728 \\
\hline 4 & $\begin{array}{l}\text { Biaya pemeliharaan } \\
\text { yang dilakukan saat } \\
\text { pengopersian }\end{array}$ & 0.163 & 0.116 & 0.057 & 0.104 & 0.412 \\
\hline
\end{tabular}

Berdasarkan matrik banding berpasangan dengan bobot kriteria, dimana jumlah nilai matrik banding berpasangan dikalikan dengan bobot. Jumlah nilai pada matrik banding berpasangan dikalikan dengan bobot kriteria merupakan nilai eugen value (1) atau lamda, maka untuk memperoleh 1 maksimum yaitu :

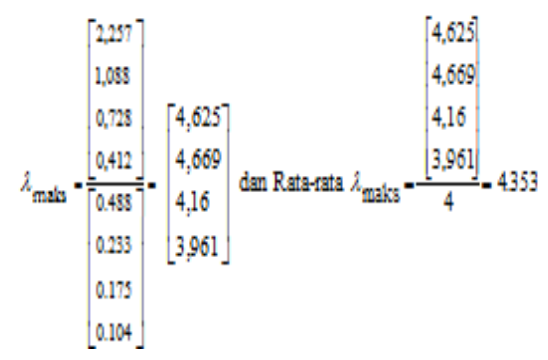

dan Rata-rata $\lambda_{\text {maks }}=\frac{\left[\begin{array}{l}4,625 \\ 4,669 \\ 4,16 \\ 3,961\end{array}\right]}{4}=4.353$ maka untuk memperoleh nilai konsistensi indeks (CI), yaitu:

$$
\text { Consisten Index }(\mathrm{CI})=\frac{\ddot{\mathrm{e}}_{\text {maks }}-\mathrm{n}}{\mathrm{n}-1}
$$

Dimana:

$1_{\text {maks }}=4,353$

$\mathrm{n}=4$ kriteria yang dibangun

sehingga nilai konsistensi indeks (CI) adalah :

$$
(\mathrm{CI})=\frac{4.353-4}{4-1}=\frac{0.353}{3}=0.117
$$

Nilai randon indeks (RI) diperoleh pada indeks random (The Analytic Hierarchy Process; Saaty, Thomas L., hal.21, 1980), maka untuk $\mathrm{n}=4$ pada tabel didapat nilai adalah 0.90

Nilai Konsistensi Ratio $(\mathrm{CR})=\frac{0.117}{0.90}$ 
Maka diperoleh untuk nilai $\mathrm{CR}=\frac{0.201}{0.90}=0 . \mathbf{B}$

Hasil akhir pada uji konsistensi ratio sebesar 0.13, hasil ini menunjukkan bahwa konsistensi kriteria yang dibangun berdasarkan kuesioner sudah memenuhi syarat dan konsistensi kriteria adalah baik.
Pada pembahasan performansi alternatif terpilih merupakan perhitungan nilai performansi untuk tiap-tiap alternatif modifikasi yang terpilih dan alternatif desain awal. Perhitungan performansi dilakukan dengan mengalikan nilai bobot pada tiap-tiap kriteria dengan hasil akhir yang diajukan pada kuesioner. Hasil perhitungan performansi untuk alternatif modifikasi yang terpilih dan desain awal dijelaskan pada tabel 8 berikut ini:

\subsection{Perhitungan Performansi}

Tabel 8 Perhitungan Performansi

\begin{tabular}{|c|c|c|c|c|c|c|}
\hline \multirow{3}{*}{ 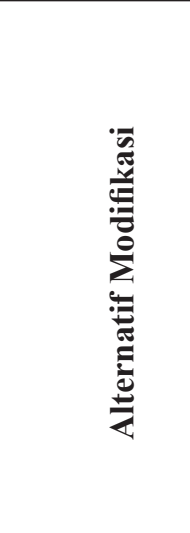 } & \multicolumn{4}{|c|}{ KRITERIA } & \multirow{3}{*}{$\approx$} & \multirow{3}{*}{ 趈 } \\
\hline & 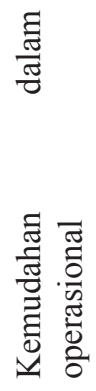 & 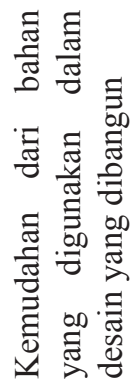 & 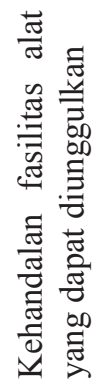 & 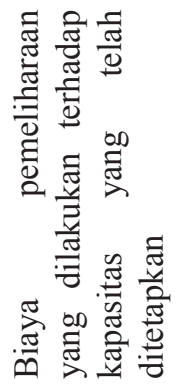 & & \\
\hline & 0,488 & 0,233 & 0,175 & 0,104 & & \\
\hline Desain awal & 22 & 35 & 25 & 40 & 27,42 & 4 \\
\hline I & 50 & 35 & 41 & 39 & 43,77 & 1 \\
\hline II & 40 & 34 & 34 & 39 & 37,44 & 2 \\
\hline III & 37 & 36 & 37 & 40 & 37,06 & 3 \\
\hline
\end{tabular}

Berdasarkan tabel performansi alternatif modifikasi di atas, maka alternatif modifikasi 1 dipertimbangkan untuk ditindak lanjuti sebagai alternatif yang terpilih dalam pengembangan alternatif desain perbaikan alat potong.

\section{Tahap Pengembangan}

Pada tahap pengembangan dilakukan 2 pembahasan yaitu analisa biaya untuk alternatif

Tabel 9

Ringkasan Biaya Pembuatan Alternatif Modifikasi

\begin{tabular}{|c|l|c|}
\hline Desain & Alternatif Modifikasi & $\begin{array}{c}\text { Biaya } \\
(\mathbf{R p})\end{array}$ \\
\hline 1 & Desain Awal & 10,000 \\
\hline 2 & Desain Modifikasi I & 218,700 \\
\hline 3 & Desain Modifikasi II & 206,700 \\
\hline 4 & Desain Modifikasi III & 203,200 \\
\hline
\end{tabular}

Pada tabel di atas terlihat bahwa adanya perbedaan tingkat pembiayaan untuk pembuatan alternatif modifikasi, pembiayaan pembuatan desain alat potong pada alternatif modifikasi I terlihat perbedaan yang lebih menonjol bila dibandingkan dengan pembiayaan pembuatan pada 38

alternatif modifikasi yang lain. modifikasi yang terpilih dan perhitungan nilai berdasarkan hasil nilai performansi.

1. Analisa biaya pada alternatif modifikasi

Biaya-biaya yang dikeluarkan untuk pembuatan setiap alternatif modifikasi pada alternative modifikasi dari proses pemotongan bahan baku keripik pisang dapat diringkas yaitu pada tabel 9 dibawah ini:

\section{Perhitungan nilai berdasarkan hasil nilai performansi}

Penentuan nilai ini merupakan perbadingan antara performansi (P) dengan biaya yang 
dikeluarkan dalam pembuatan alternatif modifikasi (C) sehingga diperoleh nilai yang menunjukkan gambaran performansi dari fasilitas alat yang dibangun. Berdasarkan hasil yang diperoleh dari analisa pada tahap sebelumnya, maka diperoleh suatu hasil performansi sebagai berikut :

Tabel 10 Nilai Pada Desain Alternatif Modifikasi

\begin{tabular}{|c|c|c|c|c|}
\hline No & $\begin{array}{c}\text { Alternatif } \\
\text { Modifikasi }\end{array}$ & Cn & Pn & Vn \\
\hline 1 & DA & 10,000 & 27,42 & 0.99 \\
\hline 2 & I & 218,700 & 43,77 & 1.00 \\
\hline 3 & II & 206,700 & 37,44 & 0.99 \\
\hline 4 & III & 203,200 & 37,06 & 0.99 \\
\hline
\end{tabular}

Hasil akhir penentuan nilai performansi pada tiap-tiap alternatif modifikasi yang terpilih bahwa tidak semuanya alternatif mempunyai nilai performansi yang lebih baik dengan desain awal. Berdasarkan tabel diatas, maka alternatif modifikasi yang mempunyai nilai tertinggi yaitu pada desain alternatif modifikasi I dengan nilai 1 dan pembiayaan pembuatan Rp 218.700,-.

\section{Tahap Presentasi}

Tahap akhir dari lima tahap rencana kerja adalah tahap presentasi yang merupakan tahap yang menjelaskan dari alternatif desain yang terbaik. Tahapan yang telah dilalui dari serangkaian analisa maka alternatif desain modifikasi yang terbaik adalah alternatif modifikasi I

\section{KESIMPULAN}

Alternatif desain perbaikan pada alat potong modifikasi adalah dengan memilih desain alternatif modifikasi I yang memiliki nilai performansi tertinggi, dan alternatif modifikasi 1 layak dipertimbangkan untuk ditindak lanjuti sebagai alternatif yang terpilih dalam pengembangan alternatif desain perbaikan alat potong. Sedangkan keunggulan desain alternatif modifikasi I ini adalah : proses pemotongan lebih cepat, perawatan mudah, hasil potongan relatif bersih dan rapi, langkah potong lancar dan ringan, keselamatan operator lebih baik

\section{DAFTAR PUSTAKA}

Dell ' Isola, Alphonse J. 1975. Value Engineering in the Construction Industry. Van Nostrand
Reinhold. New York.

Harjito, Hery Luki, [2000], " Modifikasi Sistem Rem Pada Mesin Gilas 8 Ton Ditinjau Dari Biaya Material, Biaya Produksi Dan Value Engineering di PT. Barata Indonesia ( Persero )", Tugas Akhir Program S-1, Universitas WR. Supratman, Surabaya.

Huluq, Husnul, [1999], "Penerapan Rekayasa Nilai Pada Desain Jembatan Kompleks Wisata Tawangmangu, Karanganyar di PT. Samudera Gunadharma Utama Cabang Surabaya", Tugas Akhir Program S-1, Universitas WR. Supratman, Surabaya.

John Kelly, Steven Male. 1993. Value Management In Design And Construction. E \& FN SPON. London.

Lobes, Herdiman, [2002], "Aplikasi Rekayasa Pada Mesin Flocking Modifikasi Untuk Pengembangan Alternatif Desain Perbaikan Mesin ( Studi Kasus di CV. Indo Cones Sukoharjo - Solo), Tesis Program S-2, ITS, Surabaya.

Lutfi, Muhammad, [2003], "Rancang Ulang Fasilitas Crane Untuk Meningkatkan Kecepatan Jalannya Crane Dengan Pendekatan Rekayasa Nilai", Tugas Akhir Program S-1, Universitas Muhammadiyah, Gresik.

Rh. Mitchell \& S. Chandra, "Value Engineering", Bandung, 1987.

S. Chandra Dr. Ir, "Aplikasi Value Engineering \& Analysis Pada Perencanaan Dan Pelaksanaan Untuk Mencapai Program Efisiensi”, Universitas Diponegoro, Semarang, 1987. 
Sutalaksana, IftikarZ, [2006], "Teknik Perancangan Sistem Kerja “, Edisi Kedua Penerbit ITB, Bandung.

Zimmerman, Larry W dan Glen D Hart . 1982. Value Engineering A Practical Approach For Owners, Designers And Contractors. Van Nostrand Reinhold. NewYork. 